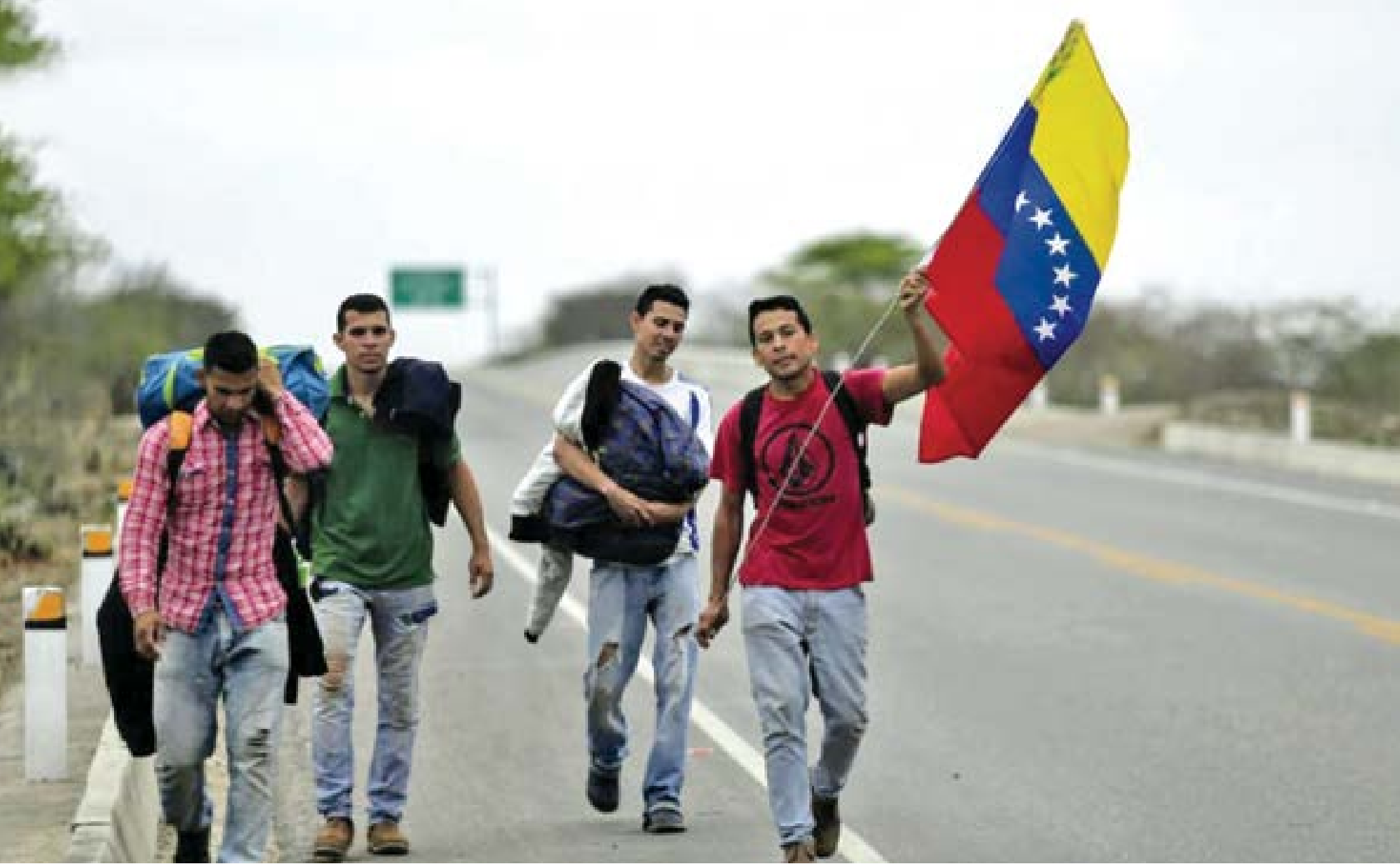

\title{
LA SECURITIZACIÓN DEL ESTADO ECUATORIANO FRENTE A LA MIGRACIÓN VENEZOLANA, ALGUNAS CONTRIBUCIONES AL DEBATE CONCEPTUAL
}

Mayo. de C.B Diego Vega Mayo. de I. Ulices Espinoza

\begin{abstract}
RESUMEN
El presente artículo académico tiene como objeto analizar las condiciones por las cuales el ser humano se ha visto obligado a emigrar hacia nuevos rumbos, en el ámbito regional y mundial, y sus efectos, con énfasis en la migracion de la población venezolana y sus consecuencias en Sudamérica, con especial atención en el Ecuador. A pesar que las causas de migrar son diversas, esta investigación se enfoca determinar cómo está constituido el fenómeno de la migración y su relación con la seguridad. En base a este análisis, surge una interrogante que será analizada acorde a lo siguiente ¿debería el Estado ecuatoriano securitizar la migración venezolana? Finalizando la investigación con una descripción de las acciones de respuesta del Estado ante la migración venezolana, empleando para ello a las instituciones del Estado, organismos internacionales y la sociedad civil, para enfrentar este fenómeno empleando las políticas de Estado o de ser necesario los instrumentos de poder a través de sus instituciones. La evaluación con indicadores establecidos por la Organización Internacional de la Migración (OIM) y otros estamentos internacionales, otorgan veracidad a esta investigación.
\end{abstract}

Surge una hipótesis a comprobar que menciona: debe el Estado ecuatoriano securitizar el fenómeno de la migración venezolana para evitar que esta incida a la seguridad, desarrollo y progreso del país.

Palabras claves: Migración, securitización, refugiados, globalización. 


\begin{abstract}
The purpose of this academic article is to analyze the conditions under which the human being has been forced to emigrate to new destinations, at the regional and global level, and its effects with emphasis on migration of the Venezuelan population and the consequences in Sudamerica, with special attention in Ecuador. Although the causes of migration are diverse, this research focuses on determining how the phenomenon of migration and its relationship with security is constituted. Based on this analysis, a question arises that will be analyzed according to the following should the Ecuadorian State securitize the Venezuelan migration? Finalizing the investigation with a description of the actions of response of the State to the Venezuelan migration, using for it the institutions of the State, international organisms and the civil society, to face this phenomenon using the policies of State or if necessary the instruments of power through their institutions. The evaluation with indicators established by the International Organization of Migration (IOM) and other international bodies, grant veracity to this investigation.
\end{abstract}

A hypothesis arises to verify that mentions as following: The Ecuadorian State must securitize the phenomenon of Venezuelan migration to avoid that this affects the security, development and progress of the country.

Keyword: Migration, securitization, refugees, globalization

\section{Introducción}

La globalización ha generado cambios radicales que han impactado significativamente en el orden mundial. Dichos impactos no solo se han manifestado en el área económica, comercial o productiva, sino que también han afectado a las relaciones sociales, la cultura, la política nacional y las relaciones internacionales, porque el espacio transnacional se ha constituido en el marco de la globalización (Ellwood, 2007). El fenómeno de la migración ha sido estudiado desde el siglo XIX, empero desde los años 90 se lo ha relacionado directamente con el tema de seguridad y es responsabilidad del Estado el reducir sus efectos adversos y aprovechar todas las potencialidades del recurso humano que se integra al país de forma social y laboral, aportando de forma activa en el nuevo escenario al que se incorpora.

Las causas sociales de la migración que afectan a América Latina han sido en su mayoría producto de conflictos internos, inestabilidad política o económica de las naciones, que junto al autoritarismo de ciertos gobiernos que vulneran incluso los derechos humanos de sus conciudadanos, han obligado a emigrar en busca de mejores oportunidades para mejorar su calidad de vida. El caso que compete es la migración venezolana y su incidencia en la región con especial interés en Colombia, Perú, Brasil y por supuesto a Ecuador, paises que se han vuelto atractivos para la migración regional, ya sea por las facilidades que brinda Ecuador por ejemplo con la política nacional de fronteras abiertas y la fortaleza del dólar ante la moneda regional; o también por la estabilidad que podría ofrecer los otros países de la región mencionados.

En ese sentido, la falta de alimentos, atención médica, educación, seguridad, por supuesto la crisis económica-social que vive un país en un momento determinado, la insatisfacción con las condiciones de vida, desempleo y trabajo informal han sido factores que impulsan la migración (David \& Jarreau, 2016). La migración venezolana como en los demás países, ha sido impulsada por los factores determinantes críticos de la migración, en especial la situación del país, motiva a que los venezolanos opten por la decisión de migrar. Se puede inferir que, dada las condiciones de vida y las necesidades apremiantes que requieren ser satisfechas, a la población le urge salir hacia otros territorios, convirtiendo a la migración como una estrategia de vida para muchos de ellos, al lograr un posible incremento de los ingresos y la reducción de la pobreza (Arouri \& Viet, 2018).

Durante el año 2018, un promedio de 2.600 venezolanos ingresó a Ecuador cada día. Según datos obtenidos hasta el final de octubre 2018 , la población de venezolanos en el país se estima en 220.000, de los cuales más de 120.000 son niños, niñas y adolescentes (UNICEF, 2018a). La responsabilidad del Estado ecuatoriano debe ser significativa acorde a los instrumentos internacionales firmados $\mathrm{y}$ en cumplimiento a lo que reza en su Carta Magna (2008) mismo que reconoce que, las personas extranjeras que se encuentran en territorio ecuatoriano, tendrán los mismos deberes y derechos que los ciudadanos ecuatorianos, por tanto, el esfuerzo del Estado ante el éxodo migratorio debe ser prioritario. Estas estrategias de los Estados deben estar acordes a las condiciones y realidades que se encuentren. En base a aquello, las estrategias no deben ser generalizadas para todos los Estados, pero si es importante que existan procesos de seguridad cooperativa que coadyuven a consolidar los esfuerzos necesarios para evitar que los efectos de la migración incidan la estabilidad política, económica, social y de seguridad de sus habitantes.

El mundo se ha venido transformando aceleradamente, sumando a sus conflictos tradicionales otros problemas más complejos y críticos que atentan 
la seguridad, el desarrollo, la economía e incluso la soberanía. Estos nuevos escenarios han transformado el carácter tradicional de la seguridad, puesto que las amenazas y riesgos ya no se definen solo en términos militares (Battaglino, 2008). Por tanto, existen una serie de factores de riesgos que pueden provocar inestabilidad e inseguridad en el régimen internacional en la medida que adquieren un carácter transnacional y afectan a otros Estados. La situación política y socioeconómica que está sufriendo Venezuela ha empujado a la emigración, con una economía en contracción, falta de acceso a la salud y alimento, hiperinflación y polarización política (Modolo \& Texido, 2018). En el caso del presente estudio la migración venezolana no es un fenómeno reciente, sin embargo, su intensidad e incidencia ha sido influyente en la región.

El presente artículo académico tiene como objetivo principal reflexionar sobre el fenómeno de la migración y la relación con la seguridad de los Estados; asimismo, se realizará un análisis sobre los acontecimientos suscitados por efecto del fenómeno de la migración a fin de evaluar la factibilidad o no de que el Estado ecuatoriano opte por aplicar procesos de securitización contra la migración venezolana; y finalmente, se analizarán las posibles acciones de respuesta del Estado ante la incidencia de la migración en el territorio nacional, considerando que ésta tiene un grado de incidencia significativa y requiere una atención especial de los Estados para evitar que exista una afectación negativa al entorno interno, exista una vulneración de los derechos humanos de los migrantes y se aprovechen la potencialidad que ofrece la migración ofrece con políticas puntuales.
Se realizó una investigación histórica descriptiva, empleando fuentes primarias, a través de una metodología de trabajo que enfocará, en describir la incidencia de la migración en el desarrollo de la humanidad y cómo ha evolucionado en el ámbito internacional y regional, dirigiendo las características más relevantes de los procesos migratorios en América del Sur, con especial atención al éxodo de inmigrantes de Venezuela en Ecuador. Como referencia de esta investigación se utilizó "el aporte de la Escuela de Copenhague a los estudios de seguridad" por Gabriel Orozco, estableciendo para ello una hipótesis de investigación a ser comprobada, que menciona: Debe el Estado ecuatoriano securitizar el fenómeno de la migración venezolana para evitar que esta incida a la seguridad, desarrollo y progreso del país.

\section{El fenómeno de la migración y la relación con la seguridad}

La migración es un fenómeno consustancial a la humanidad que ha transformado civilizaciones, ha redefinido fronteras, ha contribuido con avances tecnológicos que acarrean beneficios y desarrollo a los individuos (Castillo \& Reguant, 2017). Se destaca aspectos positivos, ya que la migración influye en el crecimiento económico de los países receptores, puesto que contribuye a incrementar la producción empleando el potencial de la fuerza de trabajo disponible. A corto y mediano plazo, la migración tiene un efecto rejuvenecedor y permite que la tasa de envejecimiento descienda, pero a largo plazo los efectos son más moderados, debido a que los migrantes también envejecen y el efecto rejuvenecedor

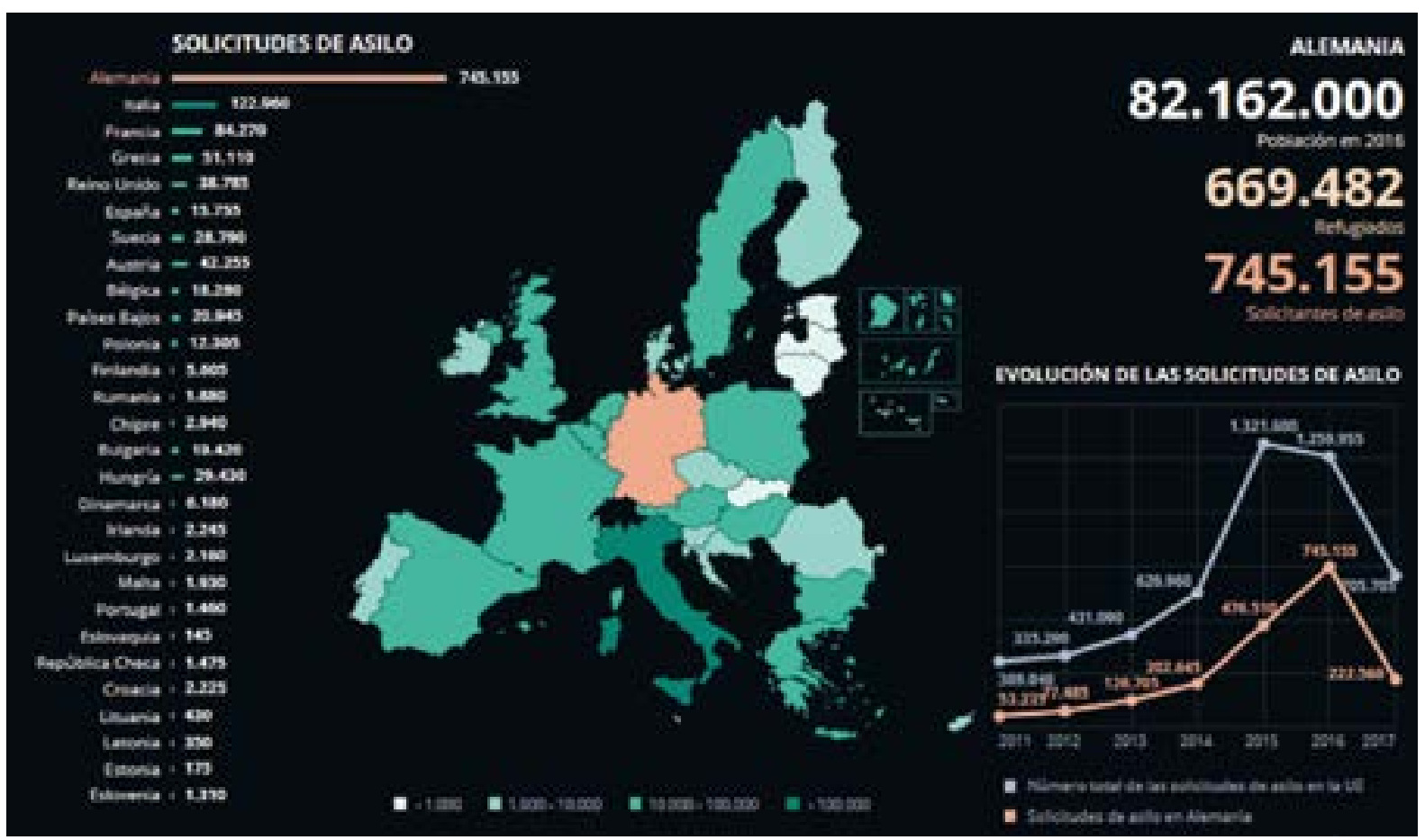

Figura 1. Solicitudes de asilo en Alemania y su evolución en el 2016.

Fuente: http://www.europarl.europa.eu/external/html/welcomingeurope/default_es.htm 
dependerá de la llegada de migrantes jóvenes (Díez \& Ramírez, 2001).

En los últimos años, se ha presentado una cantidad sin precedentes de migrantes desde África y Medio Oriente que cruzan las fronteras de sus países natales para encontrar mejores condiciones de vida alrededor del mundo. Existe un especial interés de migrar hacia Europa, huyendo de conflictos, persecución, pobreza y otras situaciones que ponen en peligro la vida y la afectación a los derechos humanos en su país de origen. A pesar de que la movilidad humana es considerada como la movilización de personas de un lugar a otro en ejercicio de su derecho a la libre circulación (...), así como también es considerada como un proceso complejo y motivado por diversas razones (voluntarias o forzadas) (OIM, 2018) ${ }^{1}$, se puede mencionar que la realidad es otra, ya que los Estados-Nación aplican estrictas políticas migratorias que dificultan el ingreso de población en esta condición a su territorio, coartando esa libre movilidad humana, empero protegiendo los intereses y objetivos fijados por los Estados mencionados.

Según la OIM, se estima que actualmente existen unos 244 millones de migrantes internacionales en todo el mundo (lo equivalente al 3,3\% de la población mundial). En el año 2015, alrededor del $75 \%$ de migrantes oscilaba en una edad laboral entre 20 a 64 años de edad. El 52\% son hombres y el 48\% mujeres. Los países con mayor cantidad de migrantes internacionales son India, México, Rusia, China y Bangladesh. Cabe recalcar que, en este año, Europa ha sido escenario más acogedor y testigo de una crisis migratoria más grave desde la Segunda Guerra Mundial, causada por los conflictos armados de grave proporción y problemas económicos en el Oriente Medio y África del Norte. La Agencia Europea de la Guardia de Fronteras y Costas recopila datos sobre los cruces ilegales de las fronteras exteriores de la Unión Europea (U.E) registrados por las autoridades nacionales. En el año 2015 y 2016, se detectaron más de 2,3 millones de cruces ilegales, incrementando el movimiento de población irregular en esta región. Sólo en el año 2016, las solicitudes de asilo en Alemania fueron las más elevadas de toda la U.E (ver figura 1). En el año 2017, el número total de cruces fronterizos ilegales en la UE se redujo a 204.700, su nivel más bajo en cuatro años (Parlamento Europeo, 2017).

Hasta fines del siglo XX, América del Sur es una región de origen, destino y tránsito de migrantes internacionales (OIM, 2017). La historia de la migración intrarregional en esta parte del continente en el siglo $\mathrm{XX}$, enfoca a un patrón migratorio intrarregional sudamericano identificado por dos subsistemas migratorios: i) la República Argentina como el receptor histórico en el Cono Sur, de corrientes procedentes de los países limítrofes (Paraguay, Bolivia, Chile, Uruguay y, en menor medida, Brasil), a los que se ha sumado Perú en los últimos decenios; y ii) los países andinos, que tiene a Venezuela como el tradicional destino migratorio y a Colombia como el emisor central, haciendo Ecuador y Perú mínimos aportes (Nicolao, 2011). En el ámbito regional, según el Reporte Mundial sobre Migración del año 2018 de la OIM, la migración intrarregional se ha incrementado en Sudamérica hasta en un $11 \%$ entre el año 2010 y 2015, asimismo, del total de migrantes internacionales en el mundo, el 4\% son de la región de América Latina y el Caribe; y de esta, aproximadamente el 70\% de toda la migración en la región es intrarregional (OIM, 2018). Las causas como los problemas sociales dados por políticas extremas, la disparidad económica y los atractivos que presenta el mercado laboral regional, impulsa a los ciudadanos a movilizarse en la región en busca de mejorar la calidad de vida.

La migración internacional ha formado parte de dinámicas históricas en la región andina. Sin embargo, en las últimas dos décadas, ha existido un despunte de los flujos migratorios en la región y se ha diversificado el perfil de los migrantes, los puntos de partida y de destino. Venezuela presenta un drástico cambio de patrón migratorio, motivado por una crisis nacional que incluye un cambio en el modelo político, un desequilibrio económico que se ha ido incluso "institucionalizando" durante los últimos años, y una descomposición social inédita para la historia republicana de Venezuela. Según la Oficina de la Organización de las Naciones Unidas para la Coordinación de Asuntos Humanitarios (OCHA) a junio de 2018, un total de 2,3 millones de venezolanos han abandonado Venezuela y se han dirigido a Colombia, Ecuador, Perú, Argentina y Brasil.

La razón que motiva a una persona a migrar varía desde la búsqueda de nuevas oportunidades para mejores sus condiciones de vida, a otras razones por las que son forzadas a salir a los venezolanos a migrar a otros países del continente y de Europa, por la inseguridad, el recrudecimiento de la criminalidad y la impunidad. Por su proximidad geográfica, una cantidad significante de migrantes se desplaza a Colombia. Estados Unidos y España. En años recientes ha habido un crecimiento de flujos hacia estos destinos históricos, pero también una diversificación hacia otros países (Panamá, Islas del Caribe, Argentina, Chile, Perú, entre otros) (OIM, 2018). Ecuador es un país de tránsito en la ruta migratoria con destino hacia otros países del sur de

1 Organización Internacional para las Migraciones 
la región, de Norte América y Europa, particularmente a España, debido a la relativa facilidad migratoria que le permite transitar por el país, puesto que la Constitución del Ecuador (2008) permite al reconocer el derecho de las personas a migrar y no considera a ningún ser humano ilegal por su condición migratoria; se eliminó el requisito de visado a los extranjeros que ingresan a Ecuador dentro de un período de noventa días para fortalecer las relaciones bilaterales y promocionar el turismo, la conocida "ciudadanía universal".

La aplicación de estas políticas de Estado, incide en un aumento significativo de la cantidad de migrantes venezolanos en Ecuador. La Cancillería ecuatoriana afirma que en los últimos cuatro años, un millón de venezolanos han ingresado al país, de los cuales aproximadamente 600.000 ingresaron en el año 2018; sin embargo, la mayoría se ha dirigido a Perú, Chile u otras naciones, hay registros de que 215.000 permanecen en territorio ecuatoriano (El Comercio, 2018), esta cantidad de población es significativa y el Estado ecuatoriano tiene un reto para enfrentarla, puesto que existe una cantidad de migrantes que ingresaron al país por puntos ilegales o simplemente no registraron su ingreso en los controles oficiales de migración. Por lo general, se han dirigido hacia las ciudades más grandes como son Quito, Guayaquil y Cuenca, empero dada a la gran afluencia de migrantes y a la condición económica social que se encuentra el país, los migrantes que recién arribaron al país están dirigiéndose a ciudades más pequeñas para diversificar las oportunidades de trabajo que pueden encontrar según el Ministerio del Interior (2018).

Según el Ministerio de Inclusión Económica y Social, inicialmente a Ecuador migró población venezolana con recursos económicos y formación académica, la cual se incluyó con relativa facilidad en la sociedad ecuatoriana. Luego arribaron al país población con títulos de técnicos y tecnólogos; y, finalmente, la última ola migratoria fue de personas que hicieron todos los esfuerzos económicos y físicos para llegar al país (Ripoll \& Navas-Alemán, 2018, pág. 4). Ante esto, la percepción de la población ecuatoriana se enfoca a ver a los venezolanos como competidores en el campo laboral, y de acuerdo a casos aislados de inseguridad, los ciudadanos ecuatorianos podrían ver a los migrantes venezolanos como un riesgo que podría incidir en la seguridad en el medio donde habitan.

La estrategia estatal ante este éxodo de ciudadanos venezolanos tiene que enfocar su esfuerzo a cumplir con lo que reza la Constitución y las leyes a favor del migrante, garantizando sus derechos, protegiendo a los grupos vulnerables, evitando discriminación y en general dando la atención que el Estado considere evitando el descuido de la población ecuatoriana, para que de ninguna manera la migración afecte negativamente a la seguridad nacional, en los campos políticos, económicos, sociales u otro indicador social de la convivencia interna (Bravo, 2015). Al considerar a Barry Buzan sobre el concepto de seguridad de la Escuela de Copenhague, el Estado tiene el derecho de declarar una condición de emergencia mediante el empleo de todos los medios necesarios para hacer frente a una amenaza, sin embargo en cumplimiento a la Constitución de la República, sus leyes y los tratados internacionales que Ecuador es signatario, no se debe considerar a la migración como una amenazas, sin embargo el Estado debe hacer todos los esfuerzos para que exista una cooperación regional para enfrentar el fenómeno de la migración, así como mantener una convivencia pacífica entre la población ecuatoriana y los migrantes venezolanos y establecer los procedimientos necesarios para regularizar su ingreso y permanencia a territorio nacional.

\section{3. ¿Debe el Estado ecuatoriano securitizar la migración venezolana, que sucede en la región?}

En el Ecuador han existido olas migratorias importantes en los últimos tiempos, debido a la legislación vigente, el paso próximo a otros países, la economía dolarizada. Una de ellas es la migración colombiana, por causas propias del conflicto interno que vivieron a través de su historia. La migración cubana que aprovechó la norma legal descrita anteriormente para tomar ventaja para que Ecuador sea un país de paso hacia los Estados Unidos; y la migración haitiana que aumentó a raíz del terremoto ocurrido en el año 2010 llegando a ingresar 17.278 ciudadanos en el año 2014.

Cabe mencionar que, la migración ha sido un tema de muchos años atrás, de la cual la poblacion ecuatoriana también fue parte de ella en aras de buscar días mejores, frente a las medidas económicas de aquellos momentos que obligaron a varios compatriotas a inmigrar hacia Europa. De esta experiencia muy difícil vivida, solo sus retinas llevan grabado desde lo difícil que fue su ingreso hasta su retornaron. Las medidas de control restrictivas impidieron a que no todos los ciudadanos que migraron tengan el derecho a quedarse. Luego del ataque terrorista a Estados Unidos EE.UU en el año 2001, motivó a que estas medidas de control migratorio sean más estrictas, en todo el mundo, especialmente en Estados Unidos y Europa.

En el año 2002, Ecuador ya visualizó los problemas que traerá a futuro, el conflicto armado interno de Colombia ya que su Libro Blanco de la Defensa (MIDENA, 2002) señala que las principales secuelas se relacionan con el incremento de desplazados y refugiados. Se evidencia en ese año que los problemas consecuentes que podría enfrentar el Ecuador obligan 
a incrementar la presencia del Estado en la frontera norte, con la presencia de sus instituciones y con las Fuerzas Armadas listas con la misión constitucional de la defensa de la soberanía e integridad territorial, cumpliendo operaciones de protección de fronteras, ya que se visualizó un ingreso masivo de población colombiana en condición de refugiados que buscaban asilo huyendo a hechos violentos y de terror en su país.

Años más tarde, la actualización del Libro Blanco de la Defensa (2006), se enfocó a que en las situaciones de riesgo se han incrementado las migraciones masivas, los flujos de refugiados y desplazados cuyas hechos han incrementado la tensión interna en el país (MIDENA, 2006). Se pone énfasis nuevamente a los efectos del conflicto interno colombiano y las repercusiones en las poblaciones fronterizas. Es así que el Estado despliega a las Fuerzas Armadas en cumplimiento a su misión de defensa de la soberanía establecido en la Constitución del año 1998, donde se intensificó el control fronterizo a través de operaciones militares, neutralizando a los grupos armados ilegales. Empero, la afluencia de refugiados colombianos sobrepasó la capacidad del Estado para un control migratorio eficaz, permitiendo así incluso su ingreso irregular.

Según Bee (2013), el país receptor de migrantes aparece, imaginariamente, como un espacio de grandes oportunidades e ingresos, pero también de rechazo ya que la búsqueda de mejores condiciones de vida motoriza los movimientos migratorios, cuyas consecuencias políticas, económicas y sociales, provocan, en muchos casos, situaciones de conflicto en el país receptor, ya sea incrementando la competencia laboral, el surgimiento de nuevos bolsones de pobreza, el aumento de la discriminación y la xenofobia, entre otras; y, este ambiente constituye en una riesgo para la estabilidad interna de la nación, por lo que surge la necesidad de que el Estado establezca medidas para enfrentar el fenómeno de los procesos migratorios de todo tipo que se presenten hacia territorio nacional, enfocado en hacer los esfuerzos para proteger a esa población vulnerable que migra.

Por otro lado, frente a los hechos de las olas migratorias venezolanas en el país y en la región, se han generado reuniones con las altas dignidades de Latinoamérica para abordar este tema con un enfoque regional, puesto que la migración venezolana tiene un área de influencia principalmente en la región andina de Colombia, Ecuador y Perú. Se ha hecho eco en el mundo esta necesidad, así lo señala El Mundo (2018), “(...) tras una reunión de cooperación internacional, países de América, Europa y Asia se comprometieron a entregar ayuda económica a Ecuador para atender la crisis migratoria venezolana (...)". El Estado ecuatoriano luego de un análisis hizo un requerimiento de quinientos millones de dólares a la comunidad internacional, para atender a miles de personas venezolanas que se encuentran en calidad de migrantes en el país, a quienes debe atender a sus necesidades básicas como salud, trabajo, educación y alimentación, esto demanda un gran esfuerzo nacional.

La U.E aprobó en el año 2018 un programa de ayuda para las provincias fronterizas por 21 millones de dólares, con la finalidad de promover la inserción de los migrantes. Los EE.UU asignaron 16 millones de dólares para la atención humanitaria en el Ecuador. (El Telégrafo, 2018). Estos recursos recibidos por Ecuador no son suficientes para lograr una mayor atención a esta población migrante, por lo que se requiere utilizar los limitados presupuestos asignados para la sociedad ecuatoriana. La delegación colombiana realizó una propuesta a finales de septiembre en el marco de la Asamblea General de Naciones Unidas, sobre la necesidad de crear un fondo regional que permita gestionar recursos para responder a la crisis migratoria venezolana. A pesar de los esfuerzos, no se ha logrado un acuerdo regional para consolidar una ayuda internacional que apoye a los Estados como Ecuador a enfrentan este fenómeno. Por otro lado, se han realizado varias reuniones en la región, buscando regular el ingreso de migrantes para tal efecto se han acordado mecanismos para regular el ingreso, de esta manera se prevé medidas para apoyar en primer plano a los venezolanos que ingresan a países acogedores y por otro lado ejercer un control prolijo a fin de determinar que las personas que ingresan no tengan antecedentes penales o judiciales.

Hoy en día, la Política de la Defensa Nacional (2018) considera a los flujos migratorios irregulares como un riesgo para el Estado ecuatoriano lo que obliga a orientar recursos no planificados para la atención a los grupos migrantes que ingresan al país, con el riesgo de una eventual confrontación social, brote de epidemias, surgimiento de actividades ilegales y otros inconvenientes propios de este fenómeno (pág. 53). Queda ahora a las instituciones del Estado, el generar estrategias, medidas y acciones efectivas, tendientes a enfrentar de la mejor manera posible este riesgo. Las acciones tomadas en los últimos meses evidencian a un Estado reactivo y no previsivo, a pesar de que las autoridades de gobierno han motivado reuniones de paises latinoamericanos para hacer frente a la migración venezolana de una forma cooperativa, manifestando su compromiso de continuar con las gestiones de apoyo a la situación migratoria de ciudadanos venezolanos en los países latinoamericanos (Trujillo, 2018). Ante esto, existe la posibilidad de que este riesgo por el ingreso masivo y sin control conlleve a futuro, problemas de seguridad referente a crimen organizado, delincuencia común, tráfico de drogas, trata de blancas y otros que, lamentablemente se pueden filtrar fácilmente en el Ecuador aprovechando que los controles a la población migrante no tienen medidas restrictivas. Aun así, el 
Estado ecuatoriano no establecería la aplicación de su poder nacional para enfrentar al riesgo de la migración irregular en su territorio.

En otros países la migración puede ser considerada como una amenaza, adoptando medidas radicales para enfrentarla. El caso reciente es la aplicación de la "Política de Cero Tolerancia" por parte del presidente de los Estados Unidos, Donald Trump, frente a las caravanas de migrantes centroamericanos que desean ingresar en territorio norteamericano en condición de asilados. Según Semple y Malkin (2018), Trump calificó a la primera caravana, que partió de Honduras el 12 de octubre, como una horda invasora. Enviando a los militares a la frontera con México y considera tomar acciones ejecutivas para cerrarles la frontera a los migrantes, incluidos aquellos que buscan asilo.

Estas acciones tomadas han sido rechazadas por los defensores de los derechos humanos, sin embargo, este país norteamericano tiene la facultad y el poder para securitizar la migración ejerciendo soberanía y precautelando al Estado y la integridad de sus habitantes. Sobre este tema, según la BBC New Mundo (2018) cita lo expresado por el presidente Trump: "Las personas pueden venir, pero deben hacerlo por los puertos de entrada". Como se puede evidenciar, si los inmigrantes pretenden llegar a ese país lo deben hacer por los pasos legales de lo contrario serán detenidos y deportados, con esto se logrará evitar que ingresen personas de manera ilegal y esto constituya un problema a futuro para el Estado.

Igualmente, existen otros Estados en la región que han definido una política estricta ante la migración. Es el caso del presidente de Brasil, Jair Bolsonaro, quien confirmó y oficializó el retiro de su país del Pacto Mundial para la Migración Segura, Ordenada y Regular establecido en el marco de la Organización de las Naciones Unidas (ONU), el 9 de enero de 2019. Esta medida se sustenta en la preservación de los valores nacionales (France24, 2019).

\section{Acciones de respuesta del Estado ante la migración venezolana}

Ante el ingreso masivo de inmigrantes venezolanos en agosto de 2018, "el Gobierno de Ecuador ha declarado estado de emergencia (no estado de excepción) relacionado con la movilidad humana en las provincias de Carchi, Pichincha y El Oro, para prestar atención urgente a los inmigrantes venezolanos en la frontera norte", para prestar, con ayuda de entidades de la ONU una "urgente atención a los flujos migratorios inusuales de venezolanos" por la frontera norte que en inicios de agosto de 2018 llego a 4.200 ingresos diarios (MREMH, 2018). Este accionar del Estado permitirá establecer los planes de contingencia y los mecanismos necesarios para la atención humanitaria en cooperación con las organizaciones del sistema de la ONU.

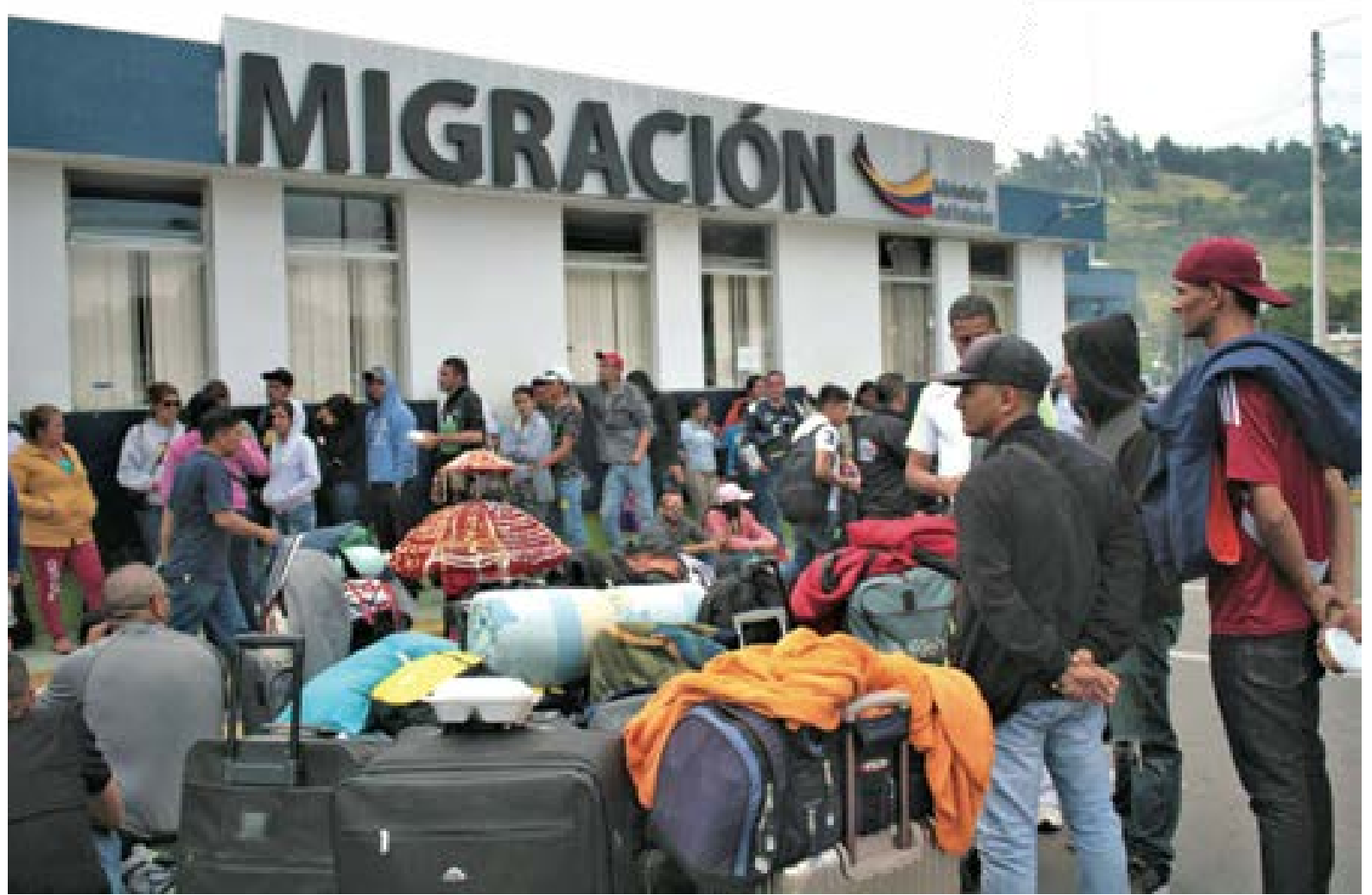

Migrantes venezolanos en la frontera colombo - ecuatoriana.

Fuente: https://www.eluniverso.com/noticias/2018/08/16/nota/6908318/ecuador-exigira-venezolanos-presentacion-pasaporte-ingresar-pais 
Estas acciones del Estado están en conformidad con las disposiciones de la Constitución de la República, la Ley Orgánica de Movilidad Humana y su Reglamento, su normativa secundaria y todas las disposiciones contenidas en los instrumentos internacionales de los cuales Ecuador es parte, acoge a todas las personas extranjeras en situación de movilidad humana, independientemente de su nacionalidad o condición migratoria (MREMH, 2018).

La atención del Estado es fundamental para el desarrollo de políticas públicas de protección y promoción de los derechos humanos y adoptando respuestas adecuadas y pragmáticas orientadas a la protección de todas las personas extranjeras establecidas en su territorio. El enfoque de posicionar a la movilidad humana se basa en la no discriminación a las personas por su condición migratoria, no a la criminalización de la migración, el reconocimiento a los aportes positivos de los migrantes a las sociedades de origen y destino; y, combatir a la xenofobia (MREMH, 2018). El emplear el aparato estatal de forma descentralizada para cumplir con una gestión efectiva a través de las coordinaciones zonales y la conformación de Mesas Interinstitucionales con el objetivo de analizar el inusual flujo migratorio de ciudadanos venezolanos que han ingresado al territorio nacional, con la participacion de las instituciones del Estado, organismos internacionales y la sociedad civil. Cabe destacar que en estas mesas interinstitucionales no forman parte las Fuerzas Armadas.

Como se puede apreciar, en los procesos tomados por parte del Estado frente al fenómeno de la migración venezolana hacia el Ecuador en el año 2018, no se ha considerado a la institución militar y el aporte de sus capacidades estratégicas para contribuir al control y supervisión de los flujos migratorios en el país. Queda claro que no se ha securitizado a este tipo de migración de la forma como lo cita la Escuela de Copenhague, gestora de la teoría crítica de la seguridad, que menciona que "la securitización consiste en un proceso mediante el cual se pretende dar la calidad o estatus de asunto de seguridad a un problema que puede atentar contra la supervivencia de un ente, ya sean individuos, conglomerados, estados o la humanidad" (Buzan, Waever, \& Wilde, 1998). Y por lo manifestado anteriormente, no es oportuna una aplicación del enfoque securitizador ante un problema que debe ser resuelto de forma cooperativa entre las instituciones del Estado más el apoyo de organismos internacionales que son expertos en este tema.

Es valedero mencionar nuevamente que la migración no es considerada como una amenaza en Ecuador. El Estado velará también por la seguridad integral de los ciudadanos extranjeros que ingresan al territorio. Para los críticos de la seguridad el objeto referente ha roto los paradigmas anteriores, enfocándose en la seguridad humana cuyas acciones del Estado son multidisciplinarias para enfrentar las nuevas amenazas y riesgos en un mundo globalizado. Así la migración constituye un tema de observancia a considerarse en las agendas estatales propendiendo a garantizar en efecto los derechos humanos de los migrantes, pero también la seguridad humana y del propio estado, lo que permitirá vivir en armonía y con una convivencia pacífica entre todos quienes habitan el territorio ecuatoriano.

Finalmente, el no securitizar al fenómeno de la migración coadyuvará en prevenir problemas futuros para el Estado, puesto que en caso que esto ocurriese y el Estado utilice todo su poder nacional para enfrentar este riesgo con políticas y directrices institucionales fuertes, se estaría atentando contra los derechos humanos de los migrantes y las consecuencias que esto conlleva. Sin embargo, debe estar claramente establecido que en caso de que el riesgo se incremente causando un peligro para la seguridad nacional, el Estado dispondrá de todo su poder nacional para enfrentar los hechos y acontecimientos que atenten contra el orden constituido y la paz relativa del Estado.

Queda como interrogante: ¿Será necesario una reforma o actualización a la norma legal vigente que rige la movilidad humana en el país? ¿Está el Estado ecuatoriano en condiciones de recibir a una cantidad infinita de ciudadanos migrantes? ¿Cuál será su límite?

\section{Conclusiones}

La migración internacional ha formado parte de dinámicas históricas en la región andina. Se requiere del comprometimiento de la región para apaliar los efectos de la migración venezolana y otros tipos de flujos migratorios irregulares que atenten contra la estabilidad de los Estados, considerando que es un fenómeno que compete a todos los Estados miembros de la región para lidiar con la crisis humanitaria, aplicando entre otras acciones de seguridad, declaratorias de emergencia y la reunión de los países miembros para monitorear el problema.

La migración está considerada como un riesgo que por el momento no afecta a la seguridad del Estado y su población. Sin embargo, el control deficiente y la permisividad de las leyes y sus fronteras, que han permitido un ingreso masivo de ciudadanos extranjeros al Ecuador, sin un control estricto formal podrían incidir en la ocurrencia de acciones que atenten contra la seguridad. La migración podría convertirse en una amenaza si las condiciones que se presentan inciden en atentar contra el Estado. Es necesario que las instituciones participen activamente ante este fenómeno, pues el sólo declarar estado de emergencia, no basta para apaliar los efectos de este éxodo masivo de migrantes. Se requiere un trabajo integral 
y cooperativo de los actores, las instituciones y las naciones afectadas, para buscar soluciones integrales que permitan reducir y contener los efectos negativos de este fenómeno.

Se comprueba la hipotesis de investigación que enfoca a que no se debe securitizar la movilidad humana expresada por la migración de ciudadanos venezolanos hacia el Ecuador. Es importante contar con leyes migratorias integrales, con reglas adecuadas que permitan el ingreso de extranjeros en calidad de migrantes al Ecuador. Se requiere el fortalecimiento a los controles migratorios en las fronteras y un control efectivo ante la movilidad humana migrante dentro del territorio ecuatoriano. Sin embargo, en caso de ser necesario, las Fuerzas Armadas requieren ser dotadas de las capacidades estratégicas más adecuadas para enfrentar los retos del presente y futuro ante los diferentes escenarios que se presenten a fin de coadyuvar los efectos de este fenómeno al Estado ecuatoriano.

\section{REFERENCIAS}

[1] BBC Nuevo Mundo. (09 de noviembre de 2018). Caravana de migrantes: Trump endurece las reglas de solicitud de asilo para los que crucen a Estados Unidos desde México. News/Mundo.

[2] Bee, E. (2013). Impacto de la migración en el desarrollo socioeconómico de América Latina. Revista Ciencia \& Futuro. Cuba: Universidad de Matanza.

[3] Bravo, G. (15 de Febrero de 2015). Las migraciones internacionales y la seguridad multidimensional en tiempos de la globalización. Obtenido de https:// scielo.conicyt.cl/scielo.php?script=sci arttext\&pid=S0719-26812015000 300013

[4] Buzan, B., Waever, Ó., \& Wilde, J. d. (1998). Security a New Framework For Analysis. London, EE.UU: Lunne Rienner Publishers.

[5] Castillo, T., \& Reguant, M. (2017) Percepciones sobre la migración venezolana: causas, España como destino, expectativas de retorno. Barcelona: MIGRACIONES 41.

[6] Córdoba, J. (2015). Una aproximación a la inmigración ecuatoriana en españa (1995-2005). Iberoamérica Social, 74.

[7] David, A., \& Jarreau, J. (2016). Determinants of emigration: Evidence from Egypt. Economicresearchforum (ERF) - Egypt.

[8] De la Vega, I., \& Vargas, C. (2014). Emigración intelectual y general en Venezuela: Una mirada desde dos fuentes de información. Obtenido de Bitácora-E Revista Electrónica Latinoamericana de Estudios Sociales, Históricos y Culturales de La Ciencia y La Tecnología: http://www. saber.ula.ve/bitstream/123456789/38748/3/ articulo3.pdf

[9] Díez, J., \& Ramírez, M. (2001). La voz de los inmigrantes. Madrid, España: IMSERSO.

[10] El Comercio. (6 de Sep de 2018). Obtenido de OEA crea grupo para responder a la crisis migratoria venezolana: https://www.elcomercio. com/actualidad/oea-respuesta-crisismigracion-venezuela.html.

[11] El Espectador . (02 de diciembre de 2018). El Mundo. Comunidad internacional ofrece ayuda económica a Ecuador para atender a los venezolanos.
[12] El Telégrafo. (01 de Diciembre de 2018). Ecuador recibe asistencia para el tema migratorio. Recuperado el 5 de Enero de 2019, de https://www. eltelegrafo.com.ec/noticias/politica/3/ ecuador-asistencia-tema-migratorio

[13] El Universo. (8 de Agosto de 2018). Ecuador declara emergencia migratoria, por llegada de 4.200 venezolanos al día. Obtenido de https://www.eluniverso. com/noticias/2018/08/08/nota/6897749/ ecuador-declara-emergencia-migratoriallegada-4200-venezolanos-dia

[14] Estado ecuatoriano. (2018). Política de Defensa Nacional. Quito.

[15] France24. (9 de Enero de 2019). Bolsonaro tras retiro del Pacto sobre Migración: "Brasil es soberano de decidir si recibe o no migrantes". Recuperado el 11 de 02 de 2019, de https://www.france24.com/ es/20190109-brasil-bolsonaro-pactomigracion-venezolanos

[16] Libro Blanco de la Defensa del Ecuador . (2006). Contextos. Quito: MDN.

[17] Libro Blanco de la Defensa del Ecuador. (2002). Escenarios. Quito: MDN.

[18] Mendoza, A. (2018). Análisis del Impacto de las Políticas Migratorias del Ecuador y su Repercusión en el Influjo Venezolano. Quito, Pichincha, Ecuador: Facultad de Derecho y Ciencias Políticas.

[19] MIDENA. (2002). Libro Blanco de la Defensa del Ecuador: Escenarios. Quito: MDN

[20] MIDENA. (2006). Libro Blanco de la Defensa: Contextos. Quito: MDN.

[21] Modolo, V., \& Texido, E. (9 de Mayo de 2018). Respuesta de Latinoamérica a la emigración venezolana. Recuperado el 11 de 02 de 2019 , de MIGRATION DATA PORTAL: https://migrationdataportal.org/blog/ espanol-respuesta-de-latinoamerica-laemigracion-venezolana

[22] MREMH. (2018). Ministerio de Relaciones Exteriores y Movilidad Humana. Quito.

[23] Nicolao, J. (14 de Marzo de 2011). Real Instituto El Cano. Obtenido de Migraciones intrarregionales en Sudamérica (ARI): http://www. realinstitutoelcano.org/wps/portal/ rielcano_es/contenido?WCM GLOBAL_CONTEXT $=$ / elcano/elcano es/zonas es/ demografia $+\mathrm{y}+$ poblacion/ari53-2011

[24] Notimérica. (20 de junio de 2016). Ecuador, modelo a seguir en la acogida de refugiados

[25] OIM. (2017). Tendencias migratorias en América del Sur. Buenos Aires.

[26] OIM. (2018). Migration Report of the International Organization for Migrantion. Le Grand-Saconnex.

[27] Orozo, G. (2000). El aporte de la Escuela de Copenhaue a los estudios de seguridad. Revista Fuerzas Armadas y Sociedad de España, 149.

[28] Parlamento Europeo. (14 de Julio de 2017). La crisis migratoria en cifras. Recuperado el 11 de Febrero de 2019, de Noticias del Parlamento Europeo: http://www.europarl.europa.eu/news/es/ headlines/society/20170629STO78630/ la-crisis-migratoria-en-cifras

[29] Ripoll, S., \& Navas-Alemán, L. (2018). Xenofobia y discriminación hacia refugiados y migrantes venezolanos en Ecuador y lecciones aprendidas para la promoción de la inclusión social Ecuador: socialscienceinaction.org.

[30] Seguridad Integral. (2014). Agenda Regional de Relaciones Exteriores y Movilidad Humana. Quito: El Telégrafo.

[31] Semple, K., \& Malkin, E. (1 de Noviembre de 2018). La caravana migrante inspira a más centroamericanos que buscan viajar a Estados Unidos. Recuperado el 11 de 02 de 2019, de The New York Times: https://www.nytimes.com/ es/2018/11/01/caravanas-migrantescentroamerica-mexico/

[32] Trujillo, Y. (13 de Octubre de 2018). Segunda reunión de países latinoamericanos por migración venezolana será en noviembre. Diario El Comercio. 